\title{
Qualidade protéica de multimisturas distribuídas em Alfenas, Minas Gerais, Brasil
}

\author{
Protein quality from "multimixture" distributed \\ in Alfenas, Minas Gerais, Brazil
}

Jane Cristina de SOUZA ${ }^{1}$

Ana Karina MAURO'

Helenice Aparecida de CARVALHO²

Márcia Regina Pereira MONTEIRO 3

Hércia Stampini Duarte MARTINO ${ }^{4}$

R E S U M O

\section{Objetivos}

O propósito do estudo foi avaliar a qualidade protéica de quatro multimisturas distribuídas para combater a desnutrição em comunidades do Município de Alfenas-MG.

\section{Métodos}

Foram utilizados ratos da raça Wistar, machos, distribuídos ao acaso em 6 grupos $(n=6)$ em gaiolas individuais de aço inox, com temperatura controlada $\left(25^{\circ} \mathrm{C}\right.$, desvio padrão $\left.=2^{\circ} \mathrm{C}\right)$, durante 14 dias. $\mathrm{O}$ grupo padrão recebeu dieta à base de caseína, o grupo controle dieta livre de nitrogênio e os outros quatro grupos experimentais receberam dietas à base de multimistura. Para avaliação da qualidade protéica foram utilizados os métodos biológicos Quociente de Eficiência Protéica, Razão Protéica Líquida, Utilização Protéica Líquida e Digestibilidade Verdadeira.

\section{Resultados}

O quociente de eficiência protéica, a razão protéica líquida e a digestibilidade dos grupos recebendo multimistura foram inferiores $(p<0,05)$ ao da caseína. A utilização protéica líquida promovida pelas dietas à base de multimisturas foi inferior à dieta à base de caseína em todos os grupos experimentais, exceto no grupo cuja multimistura apresentava maior proporção de leite em pó e não era adicionada de pó de sementes, de folha de mandioca e de casca de ovo. A digestibilidade das multimisturas foi em torno de $89 \%$, entretanto a utilização protéica foi de, aproximadamente, $27 \%$.

\footnotetext{
1 Departamento de Nutrição, Universidade Federal de Alfenas. Alfenas, MG, Brasil.

2 Departamento de Farmácia, Universidade Federal de Alfenas. Alfenas, MG, Brasil.

3 Departamento de Ciência da Nutrição, Escola de Enfermagem, Universidade Federal de Minas Gerais. Belo Horizonte, MG, Brasil.

4 Departamento de Nutrição e Saúde, Universidade Federal de Viçosa. Av. P.H. Rolfs, s/n., Campus Universitário, 36571-000, Viçosa, MG, Brasil. Correspondência para/Correspondence to: H.S.D. MARTINO.
} 


\section{Conclusão}

Conclui-se que as multimisturas apresentaram baixa retenção protéica, não sendo adequadas para o crescimento dos animais ou até mesmo para a manutenção do peso corporal em um dos grupos teste.

Termos de indexação: desnutrição; dieta; multimistura; rato.

\section{A B S T R A C T}

\section{Objective}

The study was developed to evaluate the protein quality of four multimixtures distributed in communities in Alfenas, MG, Brazil, to combat malnutrition.

\section{Methods}

Male Wistar rats were randomaly assigned to one of six groups $(n=6)$ and individually housed in stainless steel cages on controlled temperature $\left(25^{\circ} \mathrm{C}\right.$, standard deviation $\left.2^{\circ} \mathrm{C}\right)$ for 14 days. The standard group was fed a casein diet, control group was fed a free nitrogen diet and four-test groups were fed different multimixture diets. A biological assay was carried out to determine the protein quality by Protein Efficiency Ratio, Net Protein Ratio, Net Protein Utilization and True Protein Digestibility.

\section{Results}

The Multimixture test groups showed lower $(p<0.05)$ Protein Efficiency Ratio, Net Protein Ratio and digestibility than casein group. The net retention protein from multimixture test groups was lower $(p<0.05)$ than casein group, except the group fed with multimixture contained a higher powdered milk proportion and was not added with powdered seeds, leaf cassava and egg shell powders in their formula. The multimixture digestibility was roughty $89 \%$ however the protein retention was approximately $27 \%$.

\section{Conclusion}

In conclusion, the multimixture showed low protein retention, did not promote adequate animal growth and was not capable of maintaining body weight in one multimixture test-group.

Indexing terms: malnutrition; diet; multimixture; rats.

\section{N T R O D U ÇÃ O}

A desnutrição é detectada em muitos países subdesenvolvidos, especialmente entre crianças de condições socioeconômicas desfavoráveis. A ingestão inadequada de alimentos, as infecções parasitárias, as condições pobres de higiene e os baixos níveis de instrução e de poder aquisitivo são algumas das principais causas desse quadro ${ }^{1}$.

De acordo com a Organização Mundial da Saúde, mais de $30 \%$ da população infantil mundial é desnutrida. Entre as 12 milhões de mortes de menores de 5 anos registradas a cada ano, nos países em desenvolvimento, cerca de 7 milhões podem ser diretamente atribuídas à desnutrição ${ }^{1,2}$.
No Brasil, a desnutrição energético-protéica, na década de 80 , atingiu $8 \%$ dos recém-nascidos com baixo peso e $70 \%$ dos pré-escolares apresentavam algum grau de desnutrição. Segundo Madruga et al. ${ }^{3}$, a fome e a desnutrição continuam sendo as principais causas de morbimortalidade de milhões de crianças no País.

Fontes alternativas de alimentos, de baixo custo, vêm sendo desenvolvidas na tentativa de combater a desnutrição, que atinge enormes segmentos populacionais das áreas menos desenvolvidas do planeta. No Brasil, entre as diversas formas de intervenção que buscam melhorar o estado nutricional da população, o uso de multimisturas alimentares vem se destacando ${ }^{4}$.

Segundo Santos et al. ${ }^{5}$, as multimisturas consistem na junção de pós de farelos, folhas, 
cascas e sementes de diversos subprodutos a serem acrescentados à dieta, visando ao aumento de seu valor nutricional. A resolução n53/2000, da Agência Nacional de Vigilância Sanitária $\left(\right.$ ANVISA) ${ }^{6}$, regulamenta a composição e os requisitos para identificação e qualificação de misturas à base de farelos e cereais, estabelecendo os ingredientes obrigatórios e opcionais, permitindo uma grande variação na proporção e no conteúdo das multimisturas.

As carências nutricionais existentes no País, somadas à propagação do uso de multimisturas, amplamente distribuídas pela Pastoral da Criança e ao questionamento de sua utilização, vêm motivando a realização de vários estudos para avaliar o valor nutritivo de diversas multimisturas $^{4,7-9}$. Assim, o presente estudo teve como objetivo avaliar a qualidade protéica de quatro multimisturas distribuídas em diferentes comunidades do município de Alfenas, MG.

\section{M É T O D O S}

Foram coletadas quatro amostras de multimisturas, sendo uma delas produzida pelo projeto "alimentação alternativa", do Departamento de Enfermagem da Universidade Federal de Alfenas (UNIFAL/MG) e as demais produzidas pela Pastoral da Criança em três diferentes comunidades da cidade de Alfenas, MG. Cada uma das multimisturas apresentava diferenças qualitativas e quantitativas em sua composição de ingredientes (Tabela 1).

As análises da composição centesimal das multimisturas e das dietas experimentais foram realizadas em duplicata, utilizando as seguintes metodologias:

- Umidade: determinada em estufa, a $105^{\circ} \mathrm{C}$, até peso constante, segundo as normas analíticas do Instituto Adolfo Lutz ${ }^{10}$.

- Proteínas: por meio do nitrogênio total pelo método de Kjeldahl, transformando-se em percentagem de proteína pelo fator de conversão 6,25, conforme descrito pela Association of Official Analytical Chemists (AOAC) ${ }^{11}$.
Tabela 1. Ingredientes que compõem as multimisturas em g/100g. Alfenas, MG, 2002.

\begin{tabular}{llllll}
\hline Ingredientes & MM1 & MM2 & MM3 & MM4 \\
\hline Farelo de trigo & 16,66 & 17,60 & 48,21 & 16,80 \\
Farelo de arroz & 16,66 & 17,60 & 48,21 & 16,80 \\
Farinha de trigo & 16,66 & 11,72 & - & 16,80 \\
Farinha de mandioca & 16,66 & 23,45 & - & 16,80 \\
Fubá & 16,66 & 23,45 & - & 16,80 \\
Leite em pó & 16,66 & 5,86 & - & 15,69 \\
Pó de folha de mandioca & - & 0,05 & 0,78 & 0,17 \\
Semente de abóbora & - & 0,07 & - & - \\
Semente de girassol & - & - & 1,16 & - \\
Semente de melão & - & - & - & 0,07 \\
Semente de mamão & - & - & - & 0,07 \\
Casca de ovo & - & 0,20 & 1,64 & - \\
\hline
\end{tabular}

MM1: multimistura produzida na comunidade Nossa Senhora Aparecida; MM2: multimistura produzida na comunidade São Vicente; MM3: multimistura produzida na Universidade Federal de Alfenas, MG; MM4: multimistura produzida na comunidade Morada do Sol.

- Cinzas (resíduo mineral fixo): por incineração da matéria orgânica em forno mufla a $550^{\circ} \mathrm{C}$, até peso constante ${ }^{11}$.

Lipídios: por extração contínua, com éter de petróleo, em aparelho do tipo Soxhlet ${ }^{10}$.

Fibras alimentares: quantificaram-se as fibras em detergente ácido (FDA) ${ }^{11}$ e em detergente neutro (FDN) ${ }^{12}$.

\section{Ensaio biológico}

Foram utilizados 36 machos de Rattus norvegicus, raça Wistar, variedade albinus, recém desmamados, com 23 dias de idade. Os animais foram distribuídos em 6 grupos $(n=6)$, de modo que a média dos pesos entre os grupos não excedesse 10 gramas, conforme recomendações da $\mathrm{AOAC}^{11}$. Os ratos foram mantidos em gaiolas individuais, sob condições de temperatura controlada $\left(25^{\circ} \mathrm{C} \mathrm{dp}=2^{\circ} \mathrm{C}\right)$ e ciclo claro-escuro de 12 horas, recebendo água e alimento ad libitum, durante um período de 14 dias.

As dietas experimentais foram elaboradas conforme as recomendações do American Institute of Nutrition (AIN93-G) ${ }^{13}$ com teor de proteínas entre $9 \%$ a 10\%. (Tabela 2 ). O grupo padrão 
recebeu dieta com fonte protéica à base de caseína, o grupo controle dieta livre de nitrogênio e os outros grupos experimentais dietas com fonte protéica das multimisturas (MM). Os grupos receberam as seguintes denominações: grupo D1, fonte protéica multimistura M1 composta por farelo de trigo e arroz, farinha de trigo e mandioca, fubá e leite em pó; grupo D2, fonte protéica multimistura M2 composta por farelo de trigo e arroz, farinha de trigo e mandioca, fubá, leite em pó, semente de abóbora, pó de folha de mandioca e de casca de ovo; grupo D3, fonte protéica multimistura M3 composta por farelo de trigo e arroz, semente de girassol, pó de folha de mandioca e de casca de ovo; grupo D4, fonte protéica multimistura M4 composta por farelo de trigo e arroz, farinha de trigo e mandioca, fubá e leite em pó, pó de folha de mandioca e sementes de melão e mamão.

Durante o período experimental foram determinados o Quociente de Eficiência Protéica (PER), a Razão Protéica Líquida (NPR), a Utilização Protéica Líquida (NPU) e a digestibilidade verdadeira ${ }^{14}$.
O quociente de eficiência protéica foi determinado tomando-se o ganho de peso do grupo teste em relação ao consumo de proteína do grupo teste. O NPR foi calculado no $14^{\circ}$ dia do experimento, tomando-se o ganho de peso do grupo teste mais a perda de peso do grupo controle, em relação ao consumo de proteína do grupo teste.

Para a determinação do NPU foi utilizado o método da carcaça. No $14^{\circ}$ dia do experimento, os animais foram sacrificados por inalação, em um recipiente plástico com tampa, contendo algodão embebido em éter etílico. Em seguida, as carcaças foram secas em estufa com circulação de ar, a $105^{\circ} \mathrm{C}$, durante 24 horas. Após esse período as carcaças foram resfriadas, pesadas, trituradas, desengorduradas com éter de petróleo em extrator Soxhlet durante 6 horas. Posteriormente, as amostras foram pulverizadas em liquidificador para a determinação do teor de nitrogênio, retido na carcaça. Os valores de NPU foram estabelecidos pela diferença entre a retenção nitrogenada do grupo teste e do grupo controle, dividida pelo teor de nitrogênio ingerido pelo grupo teste.

Tabela 2. Composição das dietas experimentais (g/100g). Alfenas, MG, 2002.

\begin{tabular}{|c|c|c|c|c|c|c|}
\hline \multirow{2}{*}{ Ingredientes } & \multicolumn{6}{|c|}{ Dietas } \\
\hline & Padrão & Controle & D 1 & D2 & D3 & D4 \\
\hline Caseína & 17,28 & - & - & - & - & - \\
\hline Multimistura & - & - & 66,99 & 78,64 & 42,06 & 73,80 \\
\hline Amido dextrinizado & 13,20 & 13,2 & 13,20 & 8,96 & 13,20 & 10,11 \\
\hline Sacarose & 10,00 & 10,00 & 10,00 & 5,76 & 10,00 & 6,91 \\
\hline Óleo de soja & 7,00 & 7,00 & 1,58 & 1,58 & 3,19 & 4,10 \\
\hline Fibra & 5,00 & 5,00 & - & - & - & - \\
\hline Mistura mineral & 3,50 & 3,50 & 3,50 & 3,50 & 3,50 & 3,50 \\
\hline Mistura vitamínica & 1,00 & 1,00 & 1,00 & 1,00 & 1,00 & 1,00 \\
\hline Cloreto de colina & 0,25 & 0,25 & 0,25 & 0,25 & 0,25 & 0,25 \\
\hline L-cistina & 0,30 & 0,30 & 0,30 & 0,30 & 0,30 & 0,30 \\
\hline Amido de milho & 42,47 & 59,75 & 3,17 & - & 26,48 & - \\
\hline \% de proteína & 9,33 & - & 9,28 & 9,19 & 9,32 & 9,08 \\
\hline
\end{tabular}

Padrão: Dieta à base de caseína; Controle: Dieta livre de nitrogênio; D1: Dieta à base de multimistura MM1 (farelo de trigo, farelo de arroz, farinha de trigo, farinha de mandioca, fubá e leite em pó); D2: Dieta à base de multimistura MM2 (farelo de trigo, farelo de arroz, farinha de trigo, farinha de mandioca, fubá, leite em pó, pó de folha de mandioca, semente de abóbora e casca de ovo); D3: Dieta à base de multimistura MM3 (farelo de trigo, farelo de arroz, pó de folha de mandioca, semente de girassol e casca de ovo); D4: Dieta à base de multimistura MM4 (farelo de trigo, farelo de arroz, farinha de trigo, farinha de mandioca, fubá, leite em pó, pó de folha de mandioca, semente de melão e semente de mamão). 
Para o cálculo da digestibilidade, as dietas foram marcadas com carmim (100mg por $100 \mathrm{~g}$ de dieta) e as fezes coletadas do $7^{\circ}$ ao $14^{\circ}$ dia do experimento, sendo acondicionadas em recipientes individuais e mantidas sob refrigeração. Após o período de coleta, as fezes foram secas em estufa com circulação de $\mathrm{ar}$, a $105^{\circ} \mathrm{C}$, durante 24 horas. Em seguida, foram resfriadas, pesadas, desengorduradas e trituradas em liquidificador para a determinação do teor de nitrogênio.

Os resultados obtidos foram submetidos à análise de variância e as médias, quando significantes, comparadas pelo teste de Duncan, com $5 \%$ de significância, utilizando o software SAEG ${ }^{15}$. A dispersão da média foi expressa nas tabelas de resultados com desvio-padrão.
Aspectos éticos: os procedimentos experimentais foram aprovados pelo Comitê de Ética na Experimentação Animal (CEEA) da UNIFAL-MG, protocolo no 02/2002.

\section{RES ULTA D OS}

Na composição centesimal foram observados teores de proteínas de $11 \%$ a $22 \%$ e elevados teores de fibras alimentares (Tabela 3).

O teor de proteína observado esteve de acordo com o planejado, apenas o controle diferiu $(p<0,05)$ dos outros grupos experimentais. O teor de lipídios foi semelhante $(p>0,05)$, entretanto o teor de cinzas e umidade foi diferente $(p<0,05)$ entre os grupos experimentais (Tabela 4).

Tabela 3. Média e desvio-padrão da composição centesimal das multimisturas utilizadas no experimento (g/100g). Alfenas, MG, $2002 / 2003$

\begin{tabular}{|c|c|c|c|c|c|c|c|c|c|c|c|c|}
\hline \multirow{3}{*}{ Amostra } & \multicolumn{12}{|c|}{ Fibra alimentar } \\
\hline & \multicolumn{2}{|c|}{ Proteínas } & \multicolumn{2}{|c|}{ Lipídeos } & \multicolumn{2}{|c|}{ Celulose e lignina } & \multicolumn{2}{|c|}{ Hemi-celulose } & \multicolumn{2}{|c|}{ Umidade } & \multicolumn{2}{|c|}{ Cinzas } \\
\hline & $\mathrm{M}$ & $\mathrm{DP}$ & $\mathrm{M}$ & $\mathrm{DP}$ & $\mathrm{M}$ & DP & $\mathrm{M}$ & $\mathrm{DP}$ & $\mathrm{M}$ & DP & $\mathrm{M}$ & DP \\
\hline MM1 & 13,8 & 0,1 & 7,8 & 0,2 & 8,7 & 0,6 & 24,0 & 4,9 & 3,1 & 0,0 & 3,0 & 0,1 \\
\hline MM2 & 11,6 & 0,1 & 6,6 & 0,2 & 8,5 & 0,7 & 34,3 & 0,9 & 4,6 & 0,2 & 3,3 & 0,3 \\
\hline MM3 & 22,1 & 0,1 & 8,8 & 0,4 & 19,8 & 0,0 & 34,9 & 1,3 & 2,4 & 0,2 & 7,4 & 0,0 \\
\hline MM4 & 12,5 & 0,2 & 3,8 & 0,1 & 8,9 & 0,6 & 36,8 & 0,3 & 2,9 & 0,5 & 3,7 & 0,0 \\
\hline
\end{tabular}

MM1: multimistura contendo farelo de trigo, farelo de arroz, farinha de trigo, farinha de mandioca, fubá e leite em pó; MM2: multimistura contendo farelo de trigo, farelo de arroz, farinha de trigo, farinha de mandioca, fubá, leite em pó, pó de folha de mandioca, semente de abóbora e casca de ovo; MM3: multimistura contendo farelo de trigo, farelo de arroz, pó de folha de mandioca, semente de girassol e casca de ovo; MM4: multimistura contendo farelo de trigo, farelo de arroz, farinha de trigo, farinha de mandioca, fubá, leite em pó, pó de folha de mandioca, semente de melão e semente de mamão.

Tabela 4. Composição centesimal das dietas experimentais (g-100g). Alfenas, MG, 2002.

\begin{tabular}{|c|c|c|c|c|c|c|c|c|c|c|}
\hline \multirow{2}{*}{ Amostra } & \multicolumn{2}{|c|}{ Umidade* } & \multicolumn{2}{|c|}{ Proteínas* } & \multicolumn{2}{|c|}{ Lipídios* } & \multicolumn{2}{|c|}{ Cinzas* } & \multirow{2}{*}{$\begin{array}{c}\text { Carboidratos } \\
\text { totais }\end{array}$} & \multirow{2}{*}{$\begin{array}{l}\text { Fibra** } \\
\text { alimenta }\end{array}$} \\
\hline & M & DP & $\mathrm{M}$ & DP & M & DP & $\mathrm{M}$ & DP & & \\
\hline Padrão & 4,0 & $0,0^{a b c}$ & 9,3 & $0,1^{\mathrm{a}}$ & 7,0 & $0,1^{\mathrm{a}}$ & 2,0 & $0,1^{a}$ & 77,7 & 5,0 \\
\hline Controle & 3,8 & $0,0^{\text {cd }}$ & 1,8 & $0,0^{b}$ & 7,0 & $0,2^{\mathrm{a}}$ & 2,1 & $0,2^{a}$ & 85,3 & 5,0 \\
\hline D 1 & 3,8 & $0,0^{d}$ & 9,3 & $0,0^{a}$ & 7,0 & $0,3^{a}$ & 4,0 & $0,3^{b}$ & 76,0 & 21,9 \\
\hline D2 & 3,9 & $0,0^{\text {bcd }}$ & 9,2 & $0,1^{\mathrm{a}}$ & 6,9 & $0,5^{a}$ & 3,8 & $0,1^{\mathbf{b}}$ & 76,2 & 33,6 \\
\hline D3 & 4,0 & $0,0^{a b}$ & 9,3 & $0,1^{\mathrm{a}}$ & 7,1 & $0,4^{a}$ & 5,9 & $0,1^{c}$ & 73,7 & 54,7 \\
\hline D4 & 4,1 & $0,0^{a}$ & 9,1 & $0,0^{a}$ & 7,0 & $0,2^{\mathrm{a}}$ & 4,6 & $0,0^{a b}$ & 75,2 & 34,3 \\
\hline
\end{tabular}

*Médias seguidas pela mesma letra nas colunas não diferem entre si pelo teste de Duncan $(p<0,05)$.

** Calculado de acordo com a quantidade de celulose e de multimisturas adicionados nas dietas experimentais (Tabelas 2 e 3). Padrão: Dieta à base de caseína; Controle: Dieta livre de nitrogênio; D1: Dieta à base de multimistura MM1 (farelo de trigo, farelo de arroz, farinha de trigo, farinha de mandioca, fubá e leite em pó); D2: Dieta à base de multimistura MM2 (farelo de trigo, farelo de arroz, farinha de trigo, farinha de mandioca, fubá, leite em pó, pó de folha de mandioca, semente de abóbora e casca de ovo); D3: Dieta à base de multimistura MM3 (farelo de trigo, farelo de arroz, pó de folha de mandioca, semente de girassol e casca de ovo); D4: Dieta à base de multimistura MM4 (farelo de trigo farelo de arroz, farinha de trigo, farinha de mandioca, fubá, leite em pó, pó de folha de mandioca, semente de melão e semente de mamão). 
Tabela 5. Médias e desvios padrão de Ingestão alimentar e protéica, ganho de peso, PER e NPR dos grupos experimentais. Alfenas, MG, 2002.

\begin{tabular}{|c|c|c|c|c|c|c|c|c|}
\hline \multirow{2}{*}{ Dieta } & \multicolumn{2}{|c|}{ PER* } & \multicolumn{2}{|c|}{$\mathrm{NPR}^{*}$} & \multicolumn{2}{|c|}{$\mathrm{NPU}^{*}$} & \multicolumn{2}{|c|}{ Digestibilidade* } \\
\hline & M & DP & M & DP & M & DP & $M$ & DP \\
\hline Padrão & 3,1 & $0,3^{a}$ & 3,7 & $0,3^{a}$ & 59,3 & $7,6^{\mathrm{a}}$ & 96,4 & $0,5^{\mathrm{a}}$ \\
\hline D1 & 1,9 & $0,3^{b}$ & 2,8 & $0,2^{b}$ & 44,8 & $9,9^{\mathrm{ab}}$ & 93,1 & $1,0^{\mathbf{b}}$ \\
\hline D2 & 1,9 & $0,4^{b}$ & 2,8 & $0,4^{b}$ & 27,0 & $19,9^{b c}$ & 88,6 & $2,0^{c}$ \\
\hline D3 & 0,1 & $0,1^{\mathrm{c}}$ & 1,4 & $0,5^{c}$ & 15,6 & $20,3^{c}$ & 88,1 & $2,0^{c}$ \\
\hline D4 & $-0,4$ & $0,4^{\mathrm{d}}$ & 1,2 & $0,5^{c}$ & 19,6 & $25,0^{c}$ & 85,6 & $3,3^{d}$ \\
\hline
\end{tabular}

*Médias seguidas pela mesma letra nas colunas não diferem entre si pelo teste de Duncan $(p<0,05)$; Padrão: Dieta à base de caseína; D1: Dieta à base de multimistura MM1 (farelo de trigo, farelo de arroz, farinha de trigo, farinha de mandioca, fubá e leite em pó); D2: Dieta à base de multimistura MM2 (farelo de trigo, farelo de arroz, farinha de trigo, farinha de mandioca, fubá, leite em pó, pó de folha de mandioca, semente de abóbora e casca de ovo); D3: Dieta à base de multimistura MM3 (farelo de trigo, farelo de arroz, pó de folha de mandioca, semente de girassol e casca de ovo); D4: Dieta à base de multimistura MM4 (farelo de trigo, farelo de arroz, farinha de trigo, farinha de mandioca, fubá, leite em pó, pó de folha de mandioca, semente de melão e semente de mamão).

Entre os animais recebendo dieta à base de multimistura, foram encontrados valores de PER inferiores $(p<0,05)$ ao grupo padrão. Entre os grupos recebendo multimistura houve diferença $(p<0,05)$ de crescimento, de acordo com o PER, dos animais recebendo dietas D3 e D4, mas não entre D1 e D2. O resultado de crescimento avaliado pelo NPR foi semelhante ao PER, exceto entre os grupos D3 e D4 nos quais não houve diferença $(p>0,05)$ de crescimento (Tabela 5).

A digestibilidade e a retenção de nitrogênio (NPU) dos animais recebendo dieta padrão foram superiores $(p<0,05)$ às demais dietas com multimistura, exceto para NPU do grupo D1. Entre os grupos recebendo multimistura houve diferença $(p<0,05)$ de balanço de nitrogênio entre D1 e D4, mas não entre D2 e D3, sendo que o grupo D4 apresentou a menor $(p<0,05)$ digestibilidade. Já para a retenção de nitrogênio corporal, as dietas D2, D3 e D4 e, D1 e D2 não diferiram $(p<0,05)$ entre si (Tabela 5).

\section{I S C U S S Ã O}

A composição centesimal das multimisturas estudadas foi similar aos resultados de Madruga et al. ${ }^{3}$; Boaventura et al. ${ }^{7}$; Siqueira et al. ${ }^{16}$ e Glória et al. ${ }^{17}$.

Ao analisar a variação do peso corporal como reflexo global da atuação da proteína ingerida, constatou-se a superioridade da caseína em manter e aumentar o peso corporal em relação às multimisturas. Dados semelhantes foram encontrados por Bion et al. ${ }^{4}$, ao avaliar a qualidade protéica de dietas à base de arroz e feijão, acrescidas ou não de multimisturas. A diferença significativa entre valores de PER e NPR, nos grupos recebendo multimisturas, indica que a proteína presente nas mesmas não é eficiente para promover crescimento, apenas para a manutenção.

O menor crescimento dos animais recebendo dieta D3, em comparação às dietas D1 e $\mathrm{D} 2$, se deve, provavelmente, às diferenças na composição dos ingredientes das multimisturas, visto que a multimistura utilizada na dieta D3 era constituída apenas de farelos, semente e casca de ovo, já as presentes em D1 e D2 possuíam, além desses ingredientes, fubá, leite e farinhas de trigo e mandioca. Estes resultados estão de acordo com os de Glória et al. ${ }^{17}$, em que multimisturas acrescidas de produtos lácteos apresentaram melhor eficiência alimentar. Sant'Ana ${ }^{8}$ relata que os farelos de trigo e arroz apresentam altos teores de fibras insolúveis e inibidores de proteases, quando comparados com a farinha de trigo e o fubá. Segundo Monteiro et al. ${ }^{18}$, os inibidores de proteases atuam sobre tripsina e quimiotripsina, inibindo a ação digestiva e as fibras alimentares insolúveis, acarretam uma maior excreção fecal de nutrientes.

Ferreira et al. ${ }^{19}$ verificaram PER inferior ao grupo controle em ratos desnutridos recebendo dieta acrescida de multimistura, semelhante à MM3, deficiente em vitaminas e minerais. Entretanto, o grupo que recebeu multimistura na 
dieta deficiente apenas em vitaminas apresentou PER semelhante ao grupo controle.

A multimistura utilizada na composição da dieta D4, que continha basicamente os mesmos ingredientes das multimisturas presentes nas dietas D1 e D2, acrescida apenas de pó de sementes de melão e mamão, apresentou quociente de eficiência protéica inferior a todos os grupos testes, não sendo suficiente nem para a manutenção do peso dos animais. Um fator que pode ter interferido nesses resultados seria a composição das sementes de melão e mamão, que poderiam conter fatores antinutricionais e até compostos tóxicos, prejudicando o crescimento dos animais. Câmara \& Madruga9 encontraram baixas concentrações de fitato e tanino e níveis não detectáveis de aflatoxina e de ácido cianídrico em multimistura não acrescida dessas sementes, contendo $30 \%$ de farelo de trigo, 30\% de farinha de milho, 3\% de folha de mandioca, 4\% de semente de abóbora e $3 \%$ de pó de casca de ovo. Um outro fator que poderia interferir nesses resultados seria a contaminação da multimistura por microorganismos patogênicos, já que em alguns estudos, como o de Andrade \& Cordonha ${ }^{20}$ e o de Brito \& Paschoal ${ }^{21}$, foram encontrados níveis de coliformes fecais acima dos limites permitidos por legislação, além da presença de outros microorganismos patogênicos.

A digestibilidade média da multimistura foi elevada, 92\% em relação ao padrão (100\%), indicando boa hidrólise das proteínas pelas enzimas digestivas e absorção pelo organismo. Resultados semelhantes foram encontrados por Heinemann et al. ${ }^{22}$. A diferença significativa na digestibilidade entre a dieta padrão e as dietas com multimistura, pode ser atribuída à presença de fibra alimentar e a fatores antinutricionais, como fitatos, taninos, oxalato interferindo na absorção dos aminoácidos 8,19 .

Os resultados de NPU dos grupos alimentados com as dietas D2, D3 e D4 demonstram que a qualidade das proteínas das multimisturas presentes nessas dietas foi inferior à caseína para a promoção da síntese protéica, visto que o NPU mede o quanto da proteína ingerida permanece retido no organismo ${ }^{14}$.
Entre as dietas experimentais contendo multimistura acrescida de leite em pó, D1 apresentou retenção protéica líquida próxima à caseína e melhor digestibilidade, em comparação a D2 e D4, provavelmente porque aquela não foi adicionada de nenhum tipo de semente, pó de folha de mandioca e de casca de ovo. Já a multimistura D2, que continha todos esses ingredientes, além dos ingredientes da D1, não diferiu da D3, composta, basicamente, por farelos e sem adição de leite em pó. Provavelmente, a presença de fatores antinutricionais nesses constituintes interferiu no aproveitamento da proteína do leite em pó, pois essa fornece todos os aminoácidos essenciais em qualidade e quantidade, apresentando elevada digestibilidade ${ }^{23}$. Com isto, ressalta-se a importância da realização de novos estudos que investiguem a presença de fatores antinutricionais e a composição aminoacídica dos constituintes das multimisturas.

\section{O N CLUS Ã O}

A utilização das multimisturas como fonte protéica não promoveu o crescimento adequado dos animais, portanto o uso das mesmas em programas de combate à desnutrição não é justificado. A recuperação do estado nutricional, observada em alguns desses programas, se deve, provavelmente, a outros fatores, como as medidas de combate à diarréia e às parasitoses. Neste estudo, era esperado que todos os grupos experimentais que receberam dietas com multimisturas contendo leite em pó, apresentassem melhoria na qualidade protéica. A não obtenção destes resultados demonstra que houve interferência no aproveitamento das proteínas do leite, o que pode ser atribuído à presença de fatores antinutricionais contidos nas sementes e no pó de folha de mandioca, não justificando o uso na alimentação humana desses alimentos não convencionais.

\section{A GRADECIMENTOS}

Ao apoio do Programa de Bolsas de Iniciação Científica, Universidade Federal de Alfenas, processo $n^{\circ} 02 / 2002$. 


\section{REFERÊ NCIAS}

1. Nogueira-de-Almeida CA, Ricco RG, Del Ciampo LA, de Souza AM, Dutra-de-Oliveira JE. Growth and hematological studies on brazilian children of low socioeconomic level. Arch Latinoam Nutr. [periódico eletrônico], 2001 [cited 2001 Sept.]; 51(3). Available from: http://www.scielo.br

2. United Nations Children's Fundations. The state of world child health. 1998; [cited 1998]. Available from: http://www.unicef.org

3. Madruga MS, Santos HB, Bion FM. Avaliação nutricional de uma dieta suplementada com multimistura: estudo em ratos. Ciênc Tecnol Aliment. 2004; 24(1):129-33.

4. Bion FM, Pessoa DCNP, Lapa MAG, Campos FACS, Antunes NLM, López SML. Uso de uma multimistura como suplementação alimentar: estudo em ratos. Arch Latinoam Nutr. 1997; 47(3):242-7.

5. Santos LAS, Lima AMP, Passos IV, Santos LMP, Soares MD, Santos SMC. Uso e percepções da alimentação alternativa no Estado da Bahia: um estudo preliminar. Rev Nutr. 2001; 14(Supl):35-40.

6. Agência Nacional de Vigilância Sanitária. Resolução RDC no53 [online.] 2000 [citado em 15 jun 2000], Disponível em: http://www.anvisa.gov.br/legis/resol/ 2000/53_00rdc.htm

7. Boaventura GT, Chiappini CCJ, Fernandes NRA, Oliveira EM. Avaliação da qualidade protéica de uma dieta estabelecida em Quissamã, Rio de Janeiro, adicionada ou não de multimistura e de pó de folha de mandioca. Rev Nutr. 2000; 13(3): 201-9.

8. Sant'Ana LFR, Costa NMBC, Oliveira MGA, Gomez MRA. Valor nutritivo e fatores antinutricionais de multimisturas utilizadas como alternativa alimentar. Braz J Food Technol. 2000; 3(45): 129-35.

9. Câmara FS, Madruga MS. Cyanic, phitic acid, total tannin and aflatoxin contents of a Brazilian (Natal) multimistura preparation. Rev Nutr. 2001; 14(1): 33-6.

10. Instituto Adolfo Lutz. Normas analíticas, métodos químicos e físicos para análise de alimentos. 3.ed. São Paulo; 1985

11. Association of Official Analytical Chemists. Official methods of analysis of AOAC International. 16th ed. Maryland; 1997.

12. Van Soest PJ, Wine RH. Use of detergents in the analysis of fibrous feeds. IV. Determination of plant cell wall constituints. J Assoc Off Anal Chem. 1967; 50(1):50-5
13. Reeves PG, Nielsen FH, Fahey Jr. GC AIN-93 Purified diets for laboratory rodents: final report of the American Institute of Nutrition ad hoc writing Committee on the reformulation of the AIN-76A rodent diet. J Nutr. 1993; 123(11):1939-51.

14. Miller DS, Bender AE. The determination of the net utilization of proteins by shortened method. Br J Nutr. 1955; 9(4):382-8.

15. Sistema de Análises Estatísticas e Genéticas [software]. Desenvolvido pela equipe técnica da Fundação Arthur Bernardes, versão 5.0. Viçosa: Universidade Federal de Viçosa; 1993.

16. Siqueira EMA, Azevedo IT, Arruda SF, et al. Regional low-cost diet supplement improves the nutritional status os school children in a semi-arid region of Brasil. Nutr Res. 2003; 23(6):703-12.

17. Glória ECS, Almeida NAV, Costa ASV, Henrique Júnior E, Martins SL, Paula $\mathrm{H}$, et al. Avaliação protéica de uma nova multimistura com base no milho QPM BR 473. Rev Nutr. 2004; 17(3): 379-85.

18. Monteiro MRP, Moreira MA, Costa NMB, Oliveira MG, Pires CV. Avaliação da digestibilidade protéica de genótipos de soja com ausência e presença do inibidor de tripsina Kunitz e lipoxigenases. Braz J Food Technol. 2003; 6(118):99-107.

19. Ferreira HS, Assunção ML, Cardoso EPC, Moura FA. Efetividade da "multimistura" como suplemento de dietas deficientes em vitaminas e/ou minerais na recuperação ponderal de ratos submetidos à desnutrição pós-natal. Rev Nutr. 2005; 18(1):63-74.

20. Andrade AS, Cordonha MAS. Análise microbiológica da multimistura. In: Anais do Congresso Brasileiro de Ciência e Tecnologia de Alimentos; Rio de Janeiro, Brasil, Rio de Janeiro: Sociedade Brasileira de Ciência e Tecnologia de Alimentos; 1998. p.16.

21. Brito AA, Paschoal LR. Análise da multimistura preparada e distribuída em comunidade da cidade de Alfenas-MG. Nutr Brasil. 2003; 2(1):23-8.

22. Heinemann RB, Costa NMBC, Cruz R, Pirozi, MR. Valor nutricional de farinha de trigo combinada com concentrado protéico de folha de mandioca. Rev Nutr. 1998; 11(1):51-7

23. Sarwar $G$. The protein digestibility-corrected amino acid score method overestimates of proteins containing antinutritional factors and of poorly digestible proteins supplemented with limiting amino acids in rats. J Nutr. 1997; 127(5):758-64.

Recebido em: 30/11/2005

Versão final reapresentada em: 20/6/2006 Aprovado em: 31/8/2006 